\title{
Modeling and Simulation of Main Control Valve Mechanism of LNG Ship Steam Turbine
}

\author{
Hui Cao*
}

Marine Engineering College, Dalian Maritime University, No.1 Linghai Road, P.R. China

\begin{abstract}
A mathematical model and simulation analysis on main control valve mechanism of LNG ship steam turbine are carried out. A reasonable modeling division of main control valve mechanism is achieved in accordance with the idea of modular modeling, and all the models are established respectively. The modeling division includes cam lifting mechanism, oil actuator and double-valve body. The state space equations are used successfully to describe the servo system of main hydraulic valves and to reveal their dynamic process. Finally, the simulation modules are combined according to the structure and function of main control valve mechanism in Matlab/Simulink environment. By comparing experimental data and calculated data, the simulation results meet the accuracy requirements.
\end{abstract}

Keywords: LNG ship, main control valve, marine engineering, modeling and simulation, steam turbine.

\section{INTRODUCTION}

LNG ship steam power plant is very different from the traditional ship diesel engine in control and manipulation. At present, the modeling and simulation research work on relevant power of its institutions and propulsion control system need to be carried out urgently. This paper takes some research on modeling and simulation about steam turbine main control valve hydraulic servo mechanism of LNG ship including cam lifting gear, oil actuator, doublevalve and the flow characteristics for main control valve to reveal the dynamic characteristics, static characteristics and operation rules of steam turbines in the regulation process.

\section{REGULATION PRINCIPLE OF STEAM TURBINE MAIN CONTROL VALVE HYDRAULIC SERVO MECHANISM}

The steam turbine main control valve is a key equipment to achieve the manipulation for LNG ship main propulsion plant, its basic components are shown in Fig. (1), including the cam angle signal box, cam gear, lifting lever mechanism, pilot valve, oil actuator (servo cylinder), open valve lever and double-valve body (ahead valve and astern valve).

In LNG ship main propulsion control system, the superheated steam enters from the main boiler into the main control valve with open head control valve or reversing control valve by the order of RMP command [1,2]. The amount of steam into turbine is adjusted by changing the main control valve to control the steam turbine's speed and power. When the servo motor drives the cam to turn a certain clockwise angle, the lifting lever moves up and drives the

*Address correspondence to this author at the Marine Engineering College, Dalian Maritime University, Dalian 116026, P.R. China;

Tel: +8615998655555; Fax: +86-411-84726338;

E-mail: bingbinghui@sohu.com feedback lever up with taking the left end as fulcrum. It makes the pilot valve spool up and opens the servo cylinder upper inlet, So the piston will move downwards due to pressure oil, the movement of the piston is transmitted to the valve body via the open valve lever, which will reduce the ahead control valve opening or increase the astern valve opening. At this point, the feedback lever will take the right side as the fulcrum and move down. Then, the pilot valve's spool will move down gradually. When the top inlet and the bottom inlet in the servo cylinder are closed again, the piston will be in a stationary state and the valve opening will be fixed. Finally, the main steam turbine will work under a new stable condition.

\section{MODULAR MODELING DIVISION FOR MAIN CONTROL VALVE HYDRAULIC SERVO MECHANISM}

On the basis of analyzing LNG carrier propulsion control system deeply, the main control valve mechanism of LNG ship steam turbine is divided into some independent units and the corresponding mathematical model is established respectively, and the controlled object model is applied that has been established to conduct the simulation test.

Modular modeling division is a key point to main control valve hydraulic servo mechanism. In order to reveal the valve opening and closing process accurately and completely, the main control valve hydraulic servo mechanism is divided into cam lifting gear, oil valve actuator and double-valve body, and the three-part mathematical models are established respectively. Each module having a clear boundary, the output of the cam gear (shown in Fig. (1) as the movement of a lifting lever) acts as the input of oil actuator gear, whose output is also the input of double-valve (shown as a piston displacement in Fig. (1) and double-valve output is namely specific opening of ahead valve or astern valve). The used principles of modular divisions for main control valve hydraulic servo mechanism are as follows: 


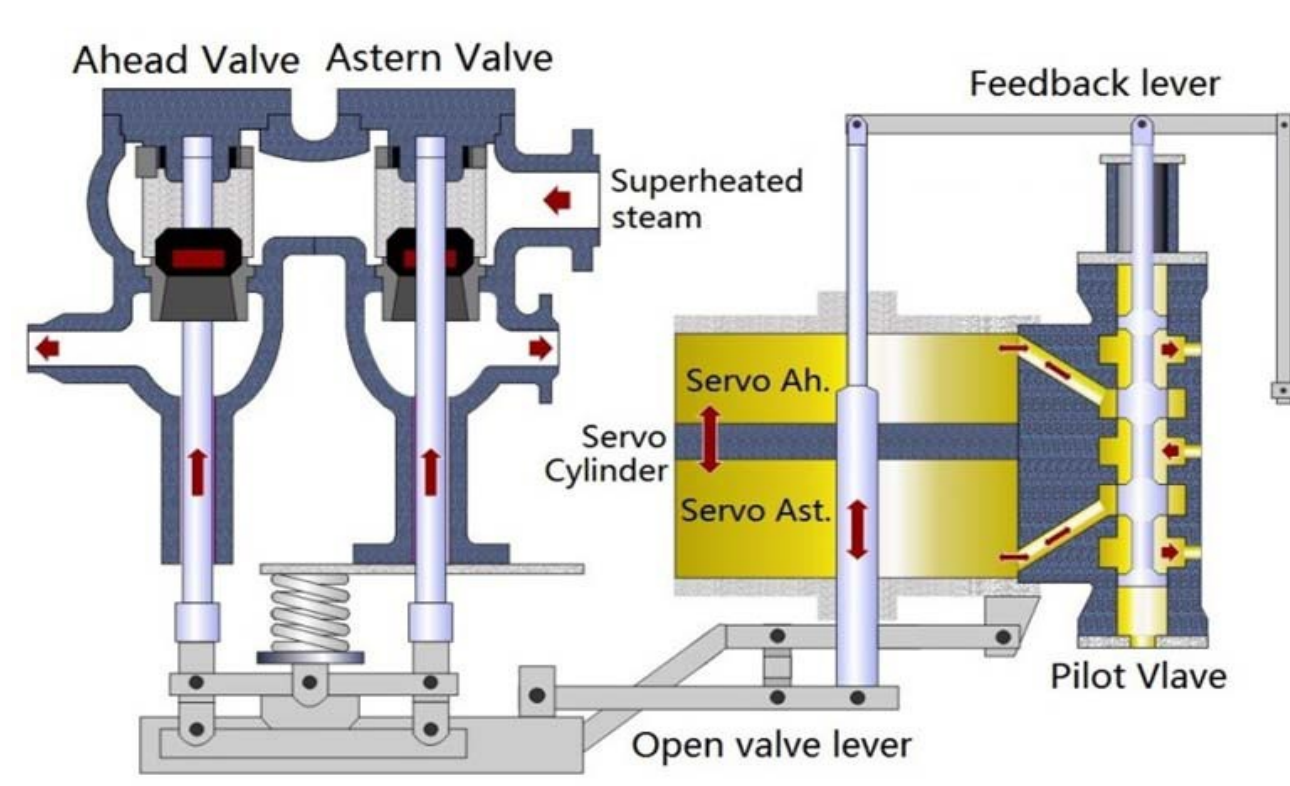

From Control Box

Fig. (1). The working principle of main control valve mechanism.

1) Every sub-module can achieve physical and logical functions completely and independently, and provide with mathematical independence and clear boundary;

2) The interaction between the sub-modules should be as small as possible, to ensure that any module's integration and isolation cannot affect the others.

\section{MAIN CONTROL VALVE HYDRAULIC SERVO MECHANISM MATHEMATICAL MODELS}

Based on the idea of modular modeling, each mathematical model is established according to the equations of energy conservation, mass conservation and momentum conservation [3]. The modeling processes for each mechanism are as follows:

\subsection{Mathematical Model of Cam Lifting Gear}

Cam lifting gear modeling finds the mathematical relationship between the cam angle and displacement of lifting lever. The mathematical relationship between the cam angle and displacement of lifting lever obtained from the experimental data of a real ship main control valves, is shown in Table 1.

Table 1. Correspondence between cam angle and lifting lever displacement.

\begin{tabular}{|c|c|c|c|}
\hline Cam Angle $\left(^{\circ}\right)$ & Displacement of Lifting Lever (mm) & Cam Angle (') & Displacement of Lifting Lever (mm) \\
\hline \hline 0 & 0 & 150 & 43.5 \\
\hline 15 & 3.25 & 160 & 64.25 \\
\hline 20 & 5.25 & 165 & -35.05 \\
\hline 30 & 7.25 & -15 & -5.25 \\
\hline 40 & 8.15 & -30 & -7.75 \\
\hline 50 & 9.05 & -40 & -9 \\
\hline 60 & 10.40 & -50 & -10.75 \\
\hline 70 & 12.05 & -60 & -13.75 \\
\hline 80 & 14.55 & -70 & -17.05 \\
\hline 90 & 16.90 & -80 & -20.75 \\
\hline 100 & 19.55 & -90 & -28.25 \\
\hline 120 & 29.05 & -100 & -39.75 \\
\hline 130 & 32.35 & -105 & -46.05 \\
\hline 140 & 35.55 & & \\
\hline
\end{tabular}

Notes: a) The counterclockwise direction of cam angle is positive, clockwise negative; the down direction of lifting lever displacement is positive, up negative. b) The maximum angle of the cam rotation counterclockwise is $165^{\circ}$; the maximum angle of clockwise rotation is $105^{\circ}$. 
Considering the possible error in measurement data, the least squares polynomial fitting is used by the data in Table $\mathbf{1}$ to achieve mathematical relationship between cam angle $\beta$ and lever displacement $\mu$, such as:

$$
\Delta u=f(\beta)
$$

The original point and the fitted curve are shown in Fig. (2).

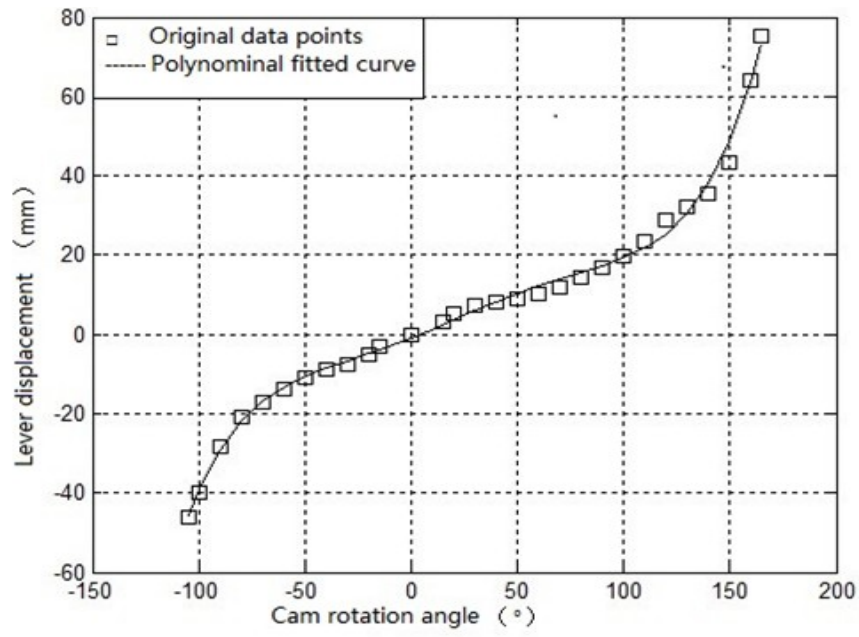

Fig. (2). Fitted curve for the correspondence between cam angle and lifting lever displacement.

\subsection{Oil Actuator State Space Equation}

When the pilot valve spool leaves balance position, the upper port and lower port open, and the hydraulic oil goes through the throttling small port rapidly. For the servo cylinder inlet cross section before and after, the application of Bernoulli equation $[4,5]$ is used:

$v_{1}^{2}-v_{0}^{2}=\frac{2 g}{\lambda}\left(p_{0}-p_{1}\right)$

where, $\lambda$ is hydraulic oil specific gravity, $\mathrm{N} / \mathrm{m}^{3} ; v_{0}, v_{1}$ are the speed of hydraulic oil through the orifice and orifice back, $\mathrm{m} / \mathrm{s} ; p_{0}, p_{1}$ are the pilot valve external oil pressure and servo cylinder piston upper pressure, respectively, $\mathrm{Pa}$.

Taking the hydraulic oil as an incompressible fluid and according to the continuity equation, the Eq. (3) can be obtained as:

$$
v_{1} A_{1}=v_{0} A_{0}
$$

where, $A_{0}, A_{1}$ are the inlet opening cross-sectional area and the cross-sectional area of back chamber in oil port.

By Eqs. (2) and (3) to get the following Eq. (4):

$$
v_{0}=\sqrt{\frac{2 g}{\lambda}\left(p_{0}-p_{1}\right)} / \sqrt{\left(A_{0} / A_{1}\right)^{2}-1}
$$

The inlet flow volume of upper port through the servo cylinder is:

$$
\begin{aligned}
& Q_{\text {上 }}=C_{v} v_{0} A_{0}=\frac{C_{v} A_{0}}{\sqrt{\left(A_{0} / A_{1}\right)^{2}-1}} \sqrt{\frac{2 g}{\lambda}\left(p_{0}-p_{1}\right)} \\
& =c A_{0} \sqrt{\frac{2 g}{\lambda}\left(p_{0}-p_{1}\right)}
\end{aligned}
$$

where, $C_{v}$ is the velocity coefficient, and $c=C_{v} / \sqrt{\left(A_{0} / A_{1}\right)^{2}-1}$ is named throttling flow coefficient, obtained through the experiment.

Due to the pilot valve spool under symmetric vertically and non-overlapping, the throttling area of slide valve is proportional to the amount of displacement $\Delta x$, the relation equation as follows:

$A_{0}=k \Delta x$

As a result,

$Q_{\text {up }}=c k \Delta x \sqrt{\frac{2 g}{\lambda}\left(p_{\mathrm{a}}-p_{1}\right)}$

In the same way, the return oil flow can be computed by Eq. (8) through the servo cylinder lower part:

$Q_{\text {down }}=c k \Delta x \sqrt{\frac{2 g}{\lambda}\left(p_{2}-p_{\mathrm{b}}\right)}$

where, $p_{\mathrm{a}}$ and $p_{\mathrm{b}}$ are upper inlet oil pressure and lower return oil pressure, respectively; $p_{1}$ is the oil pressure of the lower part of the piston in servo cylinder; $p_{2}$ is the oil pressure of the upper part of the piston in servo cylinder.

Assuming no internal leakage, so $Q_{\text {up }}=Q_{\text {down }}$, since the return oil pressure is very small, even negligible, namely $p_{\mathrm{b}}=0$; The pressure difference on both sides of the piston is $\Delta \mathrm{p}=p_{1}-p_{2}$, therefore, the upper inlet oil flow of servo cylinder is:

$Q_{\text {up }}=c k \Delta x \sqrt{\frac{2 g}{\lambda}\left(\frac{p_{\mathrm{a}}-\Delta p}{2}\right)}$

Let $C=c k \sqrt{\frac{2 g}{\lambda}}$, then, Eq. (9) can be rewritten as:

$Q_{\mathrm{up}}=\Delta x \cdot C \sqrt{\frac{p_{\mathrm{a}}-\Delta p}{2}}=f(\Delta x, \Delta p)$

Eq. (11) is obtained by linearizing Eq. (10):

$Q_{\text {up }}=K_{1} \Delta x+K_{2} \Delta p$

where,

$$
\begin{aligned}
& K_{1}=\left.\frac{\partial f}{\partial \Delta x}\right|_{\Delta x=\Delta x_{0}}=C \sqrt{\frac{p_{\mathrm{a}}-\Delta p_{0}}{2}} \\
& K_{2}=\left.\frac{\partial f}{\partial \Delta p}\right|_{\Delta p=\Delta p_{0}}=-\frac{C}{2 \sqrt{2} \sqrt{p_{\mathrm{a}}-\Delta p_{0}}}
\end{aligned}
$$


On the other hand, the relationship between the servo cylinder piston displacement $\Delta y$ and flow $Q$ as follows:

$\frac{d \Delta y}{d t}=\frac{Q_{\text {up }}}{A \rho} \quad Q_{\text {up }}=A \rho \frac{d \Delta y}{d t}$

where, $A$ is piston area, $\rho$ is fluid density.

The Eq. (14) into Eq. (11):

$\Delta p=\frac{1}{K_{2}}\left(A \rho \frac{d \Delta y}{d t}-K_{1} \Delta x\right)$

The force $F$ generated by piston pressure difference on both sides is

$F=A \Delta p=\frac{A}{K_{2}}\left(A \rho \frac{d \Delta y}{d t}-K_{1} \Delta x\right)$

The force $F$ pushes the piston to move, assuming the piston mass $M$, damping coefficient $B$, according to Newton's second law of motion, the following equation can be obtained:

$$
\begin{aligned}
& M \ddot{\Delta y}+B \dot{\Delta y}=\frac{A}{K_{2}}\left(A \rho \dot{\Delta y}-K_{1} \Delta x\right) \\
& \ddot{\Delta y}=\left(\frac{A^{2} \rho-K_{2} B}{M K_{2}}\right) \dot{\Delta y}-\frac{A K_{1}}{M K_{2}} \Delta x
\end{aligned}
$$

Considering the geometry of the rigid feedback lever:

$\Delta x=\frac{2}{3} \Delta u-\frac{1}{3} \Delta y$

Eq. (19) into Eq. (18):

$\ddot{\Delta y}=\left(\frac{A^{2} \rho-K_{2} B}{M K_{2}}\right) \dot{\Delta y}-\frac{A K_{1}}{M K_{2}}\left(\frac{2}{3} \Delta u-\frac{1}{3} \Delta y\right)$

Taking piston displacement $\Delta y$ and piston operating speed $v=\Delta y / \Delta t$ as the state variable, $\Delta \mu$ as controlling parameter, $\Delta y$ as output parameter, the state space equations are obtained as follows:

$$
\begin{aligned}
& {\left[\begin{array}{c}
\dot{\Delta y} \\
\dot{v}
\end{array}\right]=\left[\begin{array}{cc}
0 & 1 \\
\frac{A K_{1}}{3 M K_{2}} & \frac{A^{2} \rho-K_{2} B}{M K_{2}}
\end{array}\right]\left[\begin{array}{c}
\Delta y \\
v
\end{array}\right]+\left[\begin{array}{c}
0 \\
-\frac{2 A K_{1}}{3 M K_{2}}
\end{array}\right] \Delta u} \\
& \Delta y=\left[\begin{array}{ll}
1 & 0
\end{array}\right]\left[\begin{array}{c}
\Delta y \\
v
\end{array}\right]
\end{aligned}
$$

\subsection{Opening Characteristics of Double-Valve}

The movement of the servo cylinder power piston transmitted to the double-valve body via the lever, drives the stem up or down [6]. The mathematical relationship between the piston displacement amount and valve lift can be derived from the test data of real ship [7]:

1) Piston displacement $\Delta y=\left(\begin{array}{llllll}-91.5 & -79 & -57 & -41.5 & -34\end{array}\right.$ -27.5 -21.5 -18 -15.5 $-10.5-606.410 .514 .516 .218$ 20.82428 .833 .839475865 .57187128 .5150 );
2) The corresponding valve stem lift $L=(4337251814$

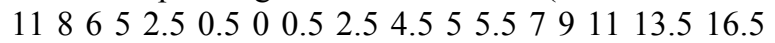
$20.526 .53033416169)$.

The mathematical relationship and curve between the valve stem lift $L$ and the piston displacement $\Delta y$ fitted with Matlab are shown in Fig. (3).

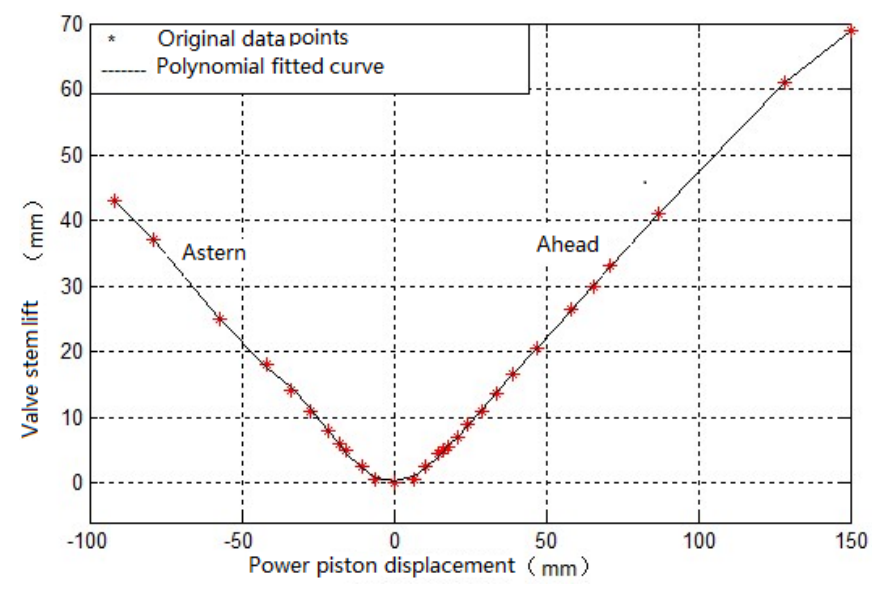

Fig. (3). Fitted curve for the correspondence between power piston displacement and valve stem lift.

\subsection{Flow Characteristics for Main Control Valve}

The varying relationships between the main control valve opening and flow are reflected by the flow characteristics. The stable control processes of main propulsion turbine, which are reflected by the accurate changes of fluid energy and flow, depend on the accurate movement of the main control valve. The working flow of the main control valve can be calculated as follows $[8,9]$ :

$$
G= \begin{cases}Y_{s t} C_{v} \sqrt{\rho_{1} p_{1}\left[(\varepsilon)^{\frac{2}{k}}-(\varepsilon)^{\frac{k+1}{k}}\right]} & \varepsilon \geq \varepsilon_{\text {cr }} \\ Y_{s t} C_{v} \sqrt{\rho_{1} p_{1}\left[\left(\varepsilon_{c r}\right)^{\frac{2}{k}}-\left(\varepsilon_{c r}\right)^{\frac{k+1}{k}}\right]} & \varepsilon \leq \varepsilon_{\text {cr }}\end{cases}
$$

where, $G$ is the steam flow through the valve, $\mathrm{kg} / \mathrm{s} ; Y_{s t}$ is the valve opening, 0 to $1 ; C_{v}$ is the valve flow obtained from the experimental data; $\rho_{1}$ is the valve inlet vapor density in $\mathrm{kg} / \mathrm{m}^{3} ; p_{1}$ is the valve inlet steam pressure(pa); $k$ is the adiabatic index, for superheated steam $k$ is about $1.3 ; \varepsilon$ is steam pressure ratio between valve outlet and inlet; $\varepsilon_{c r}$ is the critical pressure ratio, for superheated steam $\varepsilon_{c r}$ is about 0.546 .

\section{COMBINED SIMULATION FOR THE OPENING AND FLOW OF MAIN CONTROL VALVE}

The simulation modes of main control valve cam gear, oil valve actuator and double-valve body are combined in accordance with structural order. The specific opening value of an ahead or astern valve by the cam input angle can be obtained by combined simulation models to achieve a flow calculation based on a main control valve opening value [10]. The Matlab/Simulink simulation structure is shown in Fig. (4). 


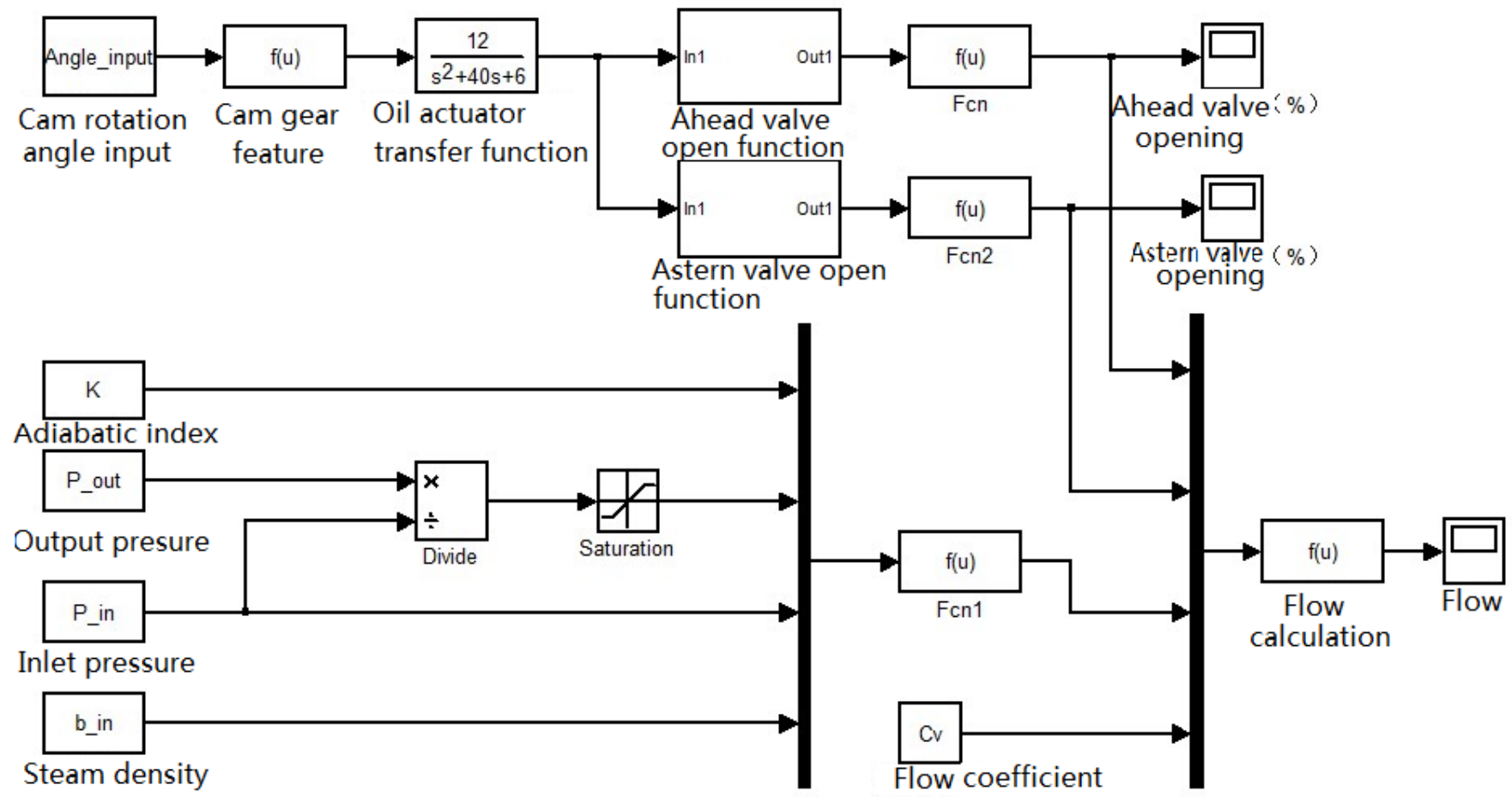

Fig. (4). Combined simulation for the main control valve.

Table 2. Comparison of experimental data and simulation data of main control valve.

\begin{tabular}{|c|c|c|c|c|c|c|c|}
\hline \multirow{2}{*}{\multicolumn{2}{|c|}{ Cam Angle $\left(^{\circ}\right)$}} & \multicolumn{3}{|c|}{ Valve Opening (\%) } & \multicolumn{3}{|c|}{ Steam Flow (kg/s) } \\
\hline & & Simulation & Experiment & Deviation & Simulation & Experiment & Deviation \\
\hline \multirow{7}{*}{$\begin{array}{c}\text { Astern } \\
\text { conditions }\end{array}$} & -105 & 100 & 100 & 0 & 20.19 & 20.21 & -0.02 \\
\hline & -100 & 84.86 & 86.01 & -1.15 & 17.13 & 17.38 & -0.25 \\
\hline & -90 & 58.26 & 58.14 & 0.12 & 11.77 & 11.85 & 0.02 \\
\hline & -70 & 31.28 & 32.56 & -1.28 & 6.32 & 6.58 & -0.26 \\
\hline & -50 & 17.65 & 18.6 & -0.95 & 3.57 & 3.85 & -0.28 \\
\hline & -30 & 10.75 & 11.63 & -0.88 & 2.17 & 2.29 & -0.12 \\
\hline & -15 & 1.37 & 1.16 & 0.21 & 0.28 & 0.24 & 0.04 \\
\hline \multirow{7}{*}{$\begin{array}{c}\text { Ahead } \\
\text { conditions }\end{array}$} & 15 & 0.68 & 0.73 & -0.05 & 0.45 & 0.48 & -0.03 \\
\hline & 40 & 7.78 & 7.83 & -0.05 & 2.09 & 2.11 & -0.02 \\
\hline & 80 & 15.86 & 16.67 & -0.81 & 4.09 & 4.31 & -0.22 \\
\hline & 120 & 38.89 & 39.13 & -0.24 & 10.01 & 10.56 & -0.55 \\
\hline & 140 & 48.18 & 48.69 & -0.51 & 13.07 & 13.18 & -0.11 \\
\hline & 160 & 86.85 & 88.41 & -1.56 & 23.4 & 23.58 & -0.18 \\
\hline & 165 & 100 & 100 & 0 & 27.11 & 27.15 & -0.04 \\
\hline
\end{tabular}

The main input parameters of the simulation model in Fig. (4) are as follows [11]:

Information data: adiabatic index $K$ and the main control valve flow coefficient $C_{\mathrm{v}}$;

Operating data: cam angle was inputted by the Angle_input parameter, main control valve inlet steam pressure was inputted by the $\mathrm{P}_{-}$in parameter, vapor density was inputted by the $b$ in parameter and the steam outlet pressure was inputted by the $\mathrm{P}_{-}$out parameter.

Main output parameters for simulation models: main control valve opening $Y_{s t}$, the corresponding steam flow $G_{s t}$.

The comparison between Simulation data and experimental data from real ship is shown in Table 2. According to the analysis of simulation data, if the pressure drop between the import and export were kept constant, the 


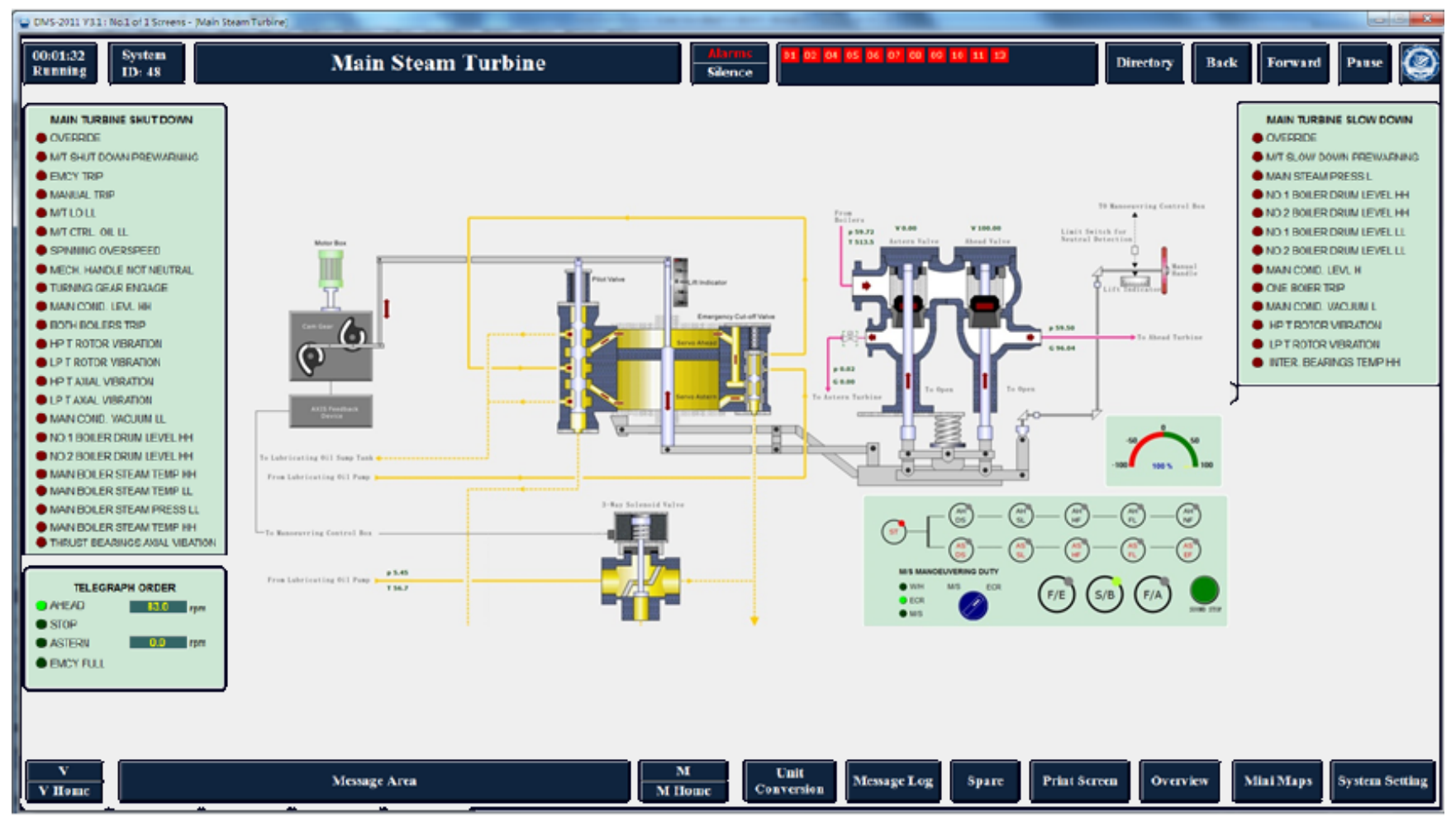

Fig. (5). Simulation effect of main control valve of LNG ship steam turbine.

main control valve flow are approximately proportional to its opening, which complies with the characteristic of linear valves.

By the analysis of the conditioned data, the dynamic changes of main parameters for the hydraulic servo mechanism of main turbine control valve in variable condition is in accordance with the law of the actual operation, which can verify the rationality of the model, while the response speed of the model can meet the requirements of real-time simulation $[12,13]$. The simulation effect of main control valve of LNG ship steam turbine is shown in Fig. (5).

\section{CONCLUSION}

This article carries out some research on modeling and simulation for main hydraulic control valves of LNG ship steam turbine, the control object are reasonably divided into cam lifting mechanism, oil actuator and double-valve body, three sub-modules in accordance with the idea of modular modeling. All the models are established respectively and combined in Matlab/Simulink environment. The simulation results of the static and dynamic characteristics are to meet the practical requirements. This approach for modeling objects is to provide platform for further analysis on dynamic characteristics of steam turbine main propulsion control system. It can also provide the simulation data support to analyze the operating performance, economic performance and control performance of steam turbine.

\section{CONFLICT OF INTEREST}

The author confirms that this article content has no conflict of interest.

\section{ACKNOWLEDGEMENTS}

This work was supported by "the Fundamental Research Funds for the Central Universities", China.

\section{REFERENCES}

[1] M.S. Donne, A.W. Pike, and R. Savry, "Application of modern methods in power plant simulation and control", Computing \& Control Engineering Journal, vol. 12, no. 2, pp. 75-84, 2001.

[2] G. Huibing, R. Guang, and Z. Jundong, Eds., A Novel Real and Simulation System on LNG Ship Propulsion, 2011, $2^{\text {nd }}$ International Conference on Artificial Intelligence, Management Science and Electronic Commerce (AIMSEC), Deng Feng, China. 2011, pp. 1829-1832.

[3] H. Wei, S. Tang, and C. Yang, Modular Simulation Technology Thermal System. Chongqing University Press: Chongqing, 1997.

[4] Y. Li, and X. Yang, "Long-term dynamic model and simulation of steam turbines", Journal of Tsinghua University, vol. 43, no. 2, pp. 281-284, 2003.

[5] A. Chaibakhsh, and A. Ghaffari, "Steam turbine model", Simulation Modeling Practice and Theory, vol.16, no. 9, pp. 1145$1162,2008$.

[6] T. Ma Wen, and Y. Wang, "Dynamic simulation of natural circulation HRSG", Journal of System Simulation, vol.19, no. 17, pp. 4055-4060, 2007.

[7] S. Yang, and L. Xing, "The flow characteristic analysis and application selection of regulating valve", Valve, no. 5, pp. 33-36, 2006.

[8] B. Halimi, and K.Y. Suh, "Engineering nonlinearity characteristic compensation for commercial steam turbine control valve using linked MARS code and Matlab Simulink", Nuclear Engineering and Design, no. 243, pp. 360-370, 2012.

[9] I.K. Choi, J.A. Kim, C.K. Jeong, J.H. Woo, J.Y. Choi, and G. Son, "Development of a digital turbine control system in a nuclear power plant", International Journal of Control, Automation, and Systems, vol. 7, no. 1, pp. 67-73, 2009. 
[10] A. Munitic, M. Orsulic, and J. Dvornik, Eds., Continuous Computer Simulation Model of the Marine Gas Turbine, Proceedings of $15^{\text {th }}$ Annual European Simulation Symposium. ESS 2003. Delft, the Netherlands, October, 2003, pp. 26-29.

[11] B. Halimi, and Y. Suh Kune, Eds., Control Engineering of Steam Turbine Valve, The $8^{\text {th }}$ International Topical Meeting on Nuclear Thermal Hydraulics, Operation and Safety, Shanghai, China, October, 2010, pp. 10-14.
[12] G. Hui Huibing, R. Guang, and Z. Jundong, Eds., A Novel Marine Engine Room Monitoring and Alarm System Integrated Simulation, 2011 International Conference on Electronic \& Mechanical Engineering and Information Technology (EMEIT), Harbin, China, 2011, pp. 2226-2229.

[13] H. B. Edgar, M. Entoni, and O. Josip, "The optimization of the steam plant by means of an engine room simulator", Scientific Journal of Maritime Research, vol. 24, no. 1, pp. 41-52, 2010.

Received: January 17, 2014

Revised: March 25, 2014

Accepted: March 26, 2014

(C) Hui Cao; Licensee Bentham Open.

This is an open access article licensed under the terms of the Creative Commons Attribution Non-Commercial License (http://creativecommons.org/licenses/ by-nc/3.0/) which permits unrestricted, non-commercial use, distribution and reproduction in any medium, provided the work is properly cited. 